\title{
Future Urban Mobility Development Framework to Maximise Benefits of Plug- in Electric Vehicle Penetration in ASEAN Countries
}

\author{
Alloysius Joko PURWANTO, Economic Research Institute for ASEAN and East Asia \\ Dian LUTFIANA, Economic Research Institute for ASEAN and East Asia
}

\begin{abstract}
Several Association of Southeast Asian Nations (ASEAN) members have recently developed strategies for low carbon-emission mobility to decrease oil import dependency. The strategies emphasise, amongst others, the importance of removing obstacles to electrification of transport and promoting market development of road plug-in electric vehicles (PEVs). Concerns about the impacts of PEV penetration include how to ensure that (i) electricity used to feed the vehicles will be produced mostly from renewable energy sources to lower carbon emissions, and (ii) additional electricity demand will not put additional stress on urban electricity grid systems.

We deduce two recommendations. First, because they use fossil-fuel energyintensive electric power, ASEAN countries need to increase urban density and compactness and stop urban sprawl, which will minimise energy use in transport, including PEVs. Generalised PEV travel cost will continue to decrease as new technology is increasingly adopted and the use of PEVs becomes more widespread. Only when a country develops renewable energy to generate electricity, such as through home-based solar photovoltaic systems, can it relax its policies on urban sprawl. Second, ASEAN countries need to avoid putting stress on the electric power grid and to maximise the use of renewables to generate power. Integrating these objectives will help determine the location of charging facilities and the measures to support mobility.
\end{abstract}

\section{Keywords}

Electric vehicles, urban mobility, renewable energy, smart city, ASEAN

\section{Introduction}

Understanding key mobility trends is crucial to implement the sustainable development agenda. To meet the needs of growing urban populations, many countries face challenges related to housing, transportation, energy systems, and other infrastructure. More than $50 \%$ of the world's population lives in urban areas; that share is expected to increase to $68 \%$ by 
2050. About $90 \%$ of this increase will take place in Asia and Africa (UN Data, 2018). Between now and 2030, the number of city dwellers in East Asia Summit countries is projected to rise from roughly 500 million to 900 million. Asia is already home to $54 \%$ of the world's urban population. The arc of urban development leans towards continuous growth, resulting in the rise of 43 megacities (with populations over 10 million) by 2030 (UN Data, 2018). At this rate, urbanisation will significantly increase demand for energy to support greater economic activity, expanding urban infrastructure, and the rising need for municipal services. As of 2018 , urban areas accounted for $65 \%$ of global energy demand and $70 \%$ of energy-related $\mathrm{CO}_{2}$ emissions (Bačeković and Østergaard, 2018).

Electric vehicles (EVs) can help mitigate climate change if they are powered by renewable energy (Chan and Wong, 2004). As part of their commitment to limit temperature rise below $2^{\circ} \mathrm{C}$ under the Paris Agreement 2015, several Association of Southeast Asian Nations (ASEAN) members set strategies to decrease oil import dependency, including by promoting EVs. ASEAN countries must remove several obstacles to EV penetration and promote market development of plug-in electric vehicles (PEVs), especially cars, powered two-wheelers, and light-duty vehicles (LDVs) or vans. However, EV penetration faces several barriers such as lack of charging stations, long charging time, and EVs' distance range, which all reduce driving mileage. As battery pack costs decrease, however, generalised costs of EV trips are becoming lower than those of internal combustion engine vehicles (ICEVs), which might increase vehicle mileage.

Promoting PEVs should not give rise to climate-change issues. Stakeholders must ensure that the electricity used to feed the vehicles is generated mostly from renewable energy sources, and that additional electricity demand will not increase stress on urban electricity grid systems. The charging management scheme will affect mobility patterns. This paper proposes a framework for future urban mobility in ASEAN countries, which will maximise the benefits of PEV penetration in urban areas.

First, the paper introduces current PEV promotion policies in several Asian and ASEAN countries, their targets, and their progress in deploying vehicles and charging infrastructure. The paper then presents several preliminary assessments of PEV penetration impacts, especially in relation to carbon-emission reduction and the load on the urban power grid. Based on several case studies of urban regions around the world, the paper elaborates the effects of EV penetration on mobility patterns by taking into account (i) PEVs' limited driving range, (ii) PEVs' required charging time, (iii) location of charging stations, and (iv) points and energy sources used to generate electricity. Finally, the paper recommends ways to develop ASEAN urban areas, especially those related to how mobility can maximise the benefits of PEV penetration.

\section{Electric Vehicle Penetration in Some Asian and ASEAN Countries}

\subsection{Policies and Current Progress}

Electric mobility is developing rapidly. The global electric car fleet is estimated to exceed 5.1 million, which is 2.0 million more than in the previous year and almost double the previous sales of new electric cars (IEA, 2019). The number of EVs is estimated to have almost tripled globally since 2005 (Raposo Alonso et al., 2019). 
China is the world's largest market for electric cars, with nearly 1.1 million sold in 2018 and, with 2.3 million units, accounts for almost half the global electric car stock, followed by Europe (1.2 million) and the United States (US) (1.1 million) (IEA, 2019). China started in 2009 with the ' 10 cities, 10,000 vehicles' business model to promote PEV development, but established targets only in June 2012: 500,000 vehicles by 2015 and 5 million by 2020. China aims to reach new EV sales shares of $7 \%-10 \%$ by $2020,15 \%-20 \%$ by 2025 , and $40 \%-50 \%$ by 2030 (Marklines, 2017).

Five business models were created in the pilot cities: state leadership in Beijing, based on public sector support; platform-led business in Shanghai, replicating international models; cooperative commercialisation in Shenzhen, based on a leasing model through strategic partnership; flexible rental in Hangzhou; and fast-charging models in Chongqing, which is close to the Three Gorge Power Grid.

In Japan, a leading EV market, government support for battery-powered EV (BEV) development started in the early 1970s. Strong government commitment to promoting EVs is reflected in heavy emphasis on research on and development of vehicle and component technologies, infrastructure, and market support for EV users. The Ministry of Economy, Trade and Industry funded the Clean Energy Vehicle Introduction Project, which provided subsidies and tax discounts for purchasing EVs (InsideEVs, 2013).

In 2017, Japan's EV production ranked fourth in the world at around 8\%, after China (50\%), Europe (21\%), and the US (17\%) (Lutsey et al., 2018). The government works with industrial stakeholders to reduce by $80 \%$ greenhouse gas (GHG) emissions from domestically produced vehicles (by $90 \%$ for passenger vehicles), including exported vehicles, by 2050 with a combination of hybrid electric vehicles (HEVs), BEVs, plug-in HEVs (PHEVs), and fuel cell EVs. Under the new policies scenario, Japan targets increasing EV sale share of all modes (excluding two- and three-wheelers) by $21 \%$ and scaling up to $37 \%$ market share under the EV30@30 scenario in 2030. To provide more charging stations throughout Japan, in 2018, the government set the goal to have fast chargers every 9.3 miles $(15 \mathrm{~km})$ or within every 19-mile $(30 \mathrm{~km})$ radius (InsideEVs, 2018a). Japan's success in the EV market is due to government commitment, strong support from the automotive industry, and user-friendly infrastructure.

The Government of India, in 2013, established the National Electric Mobility Mission Plan 2020 and, in 2015, enacted Faster Adoption and Manufacturing of (Hybrid \&) Electric Vehicles in India or FAME India. The government has announced its intention to move towards all-EV sales in 2025-2040 and, through EV30@30, to ensure that EVs will account for at least 30\% of all vehicle sales by 2030 (Lutsey et al., 2018; IEA, 2019). All vehicles, including two-wheelers, are targeted for electrification. EVs have penetrated the LDV and urban bus markets, accounting for $14 \%$ of all passenger cars and LCVs and $11 \%$ of all bus sales (IEA, 2019). As a member of the Electric Vehicle Initiative, India is dedicated to accelerating the deployment of EVs.

Delhi, the capital, will be amongst the first cities in India to fully support vehicle electrification by 2023. The Draft Delhi EV Policy 2018 aims to improve Delhi's air quality by driving rapid adoption of $\mathrm{BEV}$ s so that they contribute to $25 \%$ of all new vehicle registrations by 2023 (InsideEVs, 2018b). 
Only two ASEAN countries produce and commercialise PEVs - Thailand and Malaysia. Thailand's first PEV development roadmap - the Electric Vehicle Promotion Plan - was approved by the government in March 2015. In 2017, the Board of Investment (Bol) approved incentives for manufacturers of BEVs, HEVs, and PHEVs, mostly in the form of corporate tax exemptions for 5-8 years. The project to develop next-generation automotive vehicles, focusing on PEVs, was included in the Eastern Economic Corridor, approved in February 2018, to spur investment. In March 2019, the Bol agreed to renew the investment package for HEVs to attract more investment to PEV production. Investors must apply to produce HEVs in 2019 and assemble BEVs within 3 years. HEV and PHEV sales rose by $24.7 \%$ in 2017 to 11,945 units whilst BEV sales reached 165 units (Nicholls et al., 2018). All vehicles sold in that year totalled 870,748 units. By 2036, Thailand targets having 1.2 million electric cars on its streets and setting up 690 charging stations.

Malaysia started its PEV programme earlier than Thailand. In 2011, the government exempted from excise duties and import taxes completely built-up, fully imported hybrid cars to encourage manufacturers to invest in PEV production in the country. After the policy failed to boost foreign investment, the government abandoned it in 2014 and extended it only for completely knocked-down models assembled in Malaysia. The government now prefers to deal with manufacturers individually, a strategy that appears to work with several foreign original equipment manufacturers.

A recent tripartite agreement between TNB Energy Services Sdn Bhd (TNBES), Petronas Dagangan Bhd (PetDag), and GreenTech Malaysia resulted in the installation of 100 charging stations across the country by 2018. By the end of 2018, 251 PEV charging stations had been built across the peninsula (Weng, 2019). GreenTech Malaysia is under the purview of the Ministry of Energy, Science, Technology, Environment and Climate Change to spearhead the development and promotion of green technology as a strategic engine for socio-economic growth in line with the Green Technology Master Plan 2017-2030. The number of new registered hybrid vehicles, including conventional HEVs and, in recent years, PHEVs, increased from 138 in 2010 to more than 9,000 in 2017. Malaysia aims to build 125,000 charging stations by 2020 .

In the second half of 2018, the Government of Indonesia was to have issued a presidential decree on deploying EVs but it has not yet materialised. Despite the lack of a formal development framework, the Ministry of Industry told a newspaper that the government would target sales of 400,000 EVs by 2025 to reduce GHG emissions by $29 \%$ by 2030 (Akhyar, 2019). One source mentions that 400,000 PEVs would be produced domestically by then. Other sources estimate that around 2 million electric-powered two-wheelers would be sold by 2025. Jakarta has around 1,000 charging stations, built by the PLN (State Electricity Company).

\subsection{Impacts of PEV Penetration on Reducing $\mathrm{CO}_{2}$ Emissions}

Unless power generation is decarbonised, the effect of reducing $\mathrm{BEVs}^{\prime} \mathrm{CO}_{2}$ emissions will be limited in Thailand, Malaysia, Viet Nam, and Indonesia, which are largely dependent on coaland, to some extent, gas-fired power plants. Transitioning from ICEVs to EVs would be a huge advantage (Suehiro and Purwanto, forthcoming). 
PEV penetration would not much change the energy self-sufficiency ratio of those countries since the decrease in imports of petroleum products used as transport fuel, e.g., gasoline and diesel, would be cancelled by increasing imports of coal and natural gas used to generate electricity. PEV penetration would, however, considerably improve those countries' import bills. The generous subsidies needed for PEV penetration and the large investment in low-carbon power supply might put pressure on government finances (Suehiro and Purwanto, forthcoming).

\subsection{Impacts of PEV Penetration on the Urban Power Grid}

ICEV users benefit from well-established refuelling station networks nearly everywhere. In contrast, PEV charging infrastructure is in its early development stage, especially in ASEAN countries.

The expansion of PEVs and their demand for charging facilities have become increasingly important. The associated electricity demand will affect energy markets and the grid infrastructure. Studies on Portugal (Nunes, 2015) and the European Union (Kasten and Purwanto, 2016) show the impact of PEVs on the power grid once they make up $5 \%-10 \%$ of total road vehicles.

PEVs' environmental performance is better than conventional vehicles' when additional electricity demand is met by a low-carbon energy mix (Suehiro and Purwanto, forthcoming). China, the PEV front runner in Asia, is struggling to curb its share of coal-fired electric energy from $75 \%$ to $50 \%$ and to increase that of renewable sources from $25 \%$ to $50 \%$ by 2030 , bringing down power generation carbon intensity by one-third and ensuring that PEVs will be less carbon intensive than they are now. China uses more electricity from coal-fired generating plants during fast-charging peak demand periods and after working hours in the evening. Slow charging during off-peak hours, when energy from renewables such as wind turbines is available, would reduce $\mathrm{CO}_{2}$ emissions (Chen et al., 2018).

When and how PEVs are charged determine which generation plants satisfy additional electricity demand and have an impact on emissions. Depending on their total system and marginal costs, different types of power plants may increase production. Including this charging scheme in the analysis might change the calculation results.

Uncontrolled or user-driven charging occurs mostly after work in the evening, when electricity demand is already high, increasing system load and costs of utilities (Brandmayr et al., 2017). User-driven charging raises severe concerns about generation adequacy and may jeopardise the stability of the power system (Schill and Gerbaulet, 2015). Fast-charging stations use large amounts of power for short periods of time, meaning that expensive upgrades will be needed for a relatively low use rate (Hall and Lutsey, 2017). In the US, if PEVs constitute $25 \%$ of all road vehicles, uncontrolled charging will increase electricity peak demand by $19 \%$, but spreading charging over the evening hours will increase demand by only $0 \%-6 \%$ (Fitzgerald, 2017).

Both concerns - inadequate reduction of $\mathrm{CO}_{2}$ emissions and the increasing load on the local grid - clearly need to be solved by managing charging. Possible charging management schemes follow:

- Off-peak or network-oriented charging. Policies and structures that encourage offpeak period charging might include workplace or daytime charging and night- 
time home charging to avoid network congestion and physical capacity constraints.

- Cost-oriented charging. This strategy would reduce PEV charging cost by shifting the charging time to periods of low energy prices. PEV owners would benefit from low energy costs and smoothing of load patterns as costs are low when demand is low. If low-cost periods are dominated by conventional generation, however, negative environmental effects could result.

- Smart charging. This includes controlled charging and demand response. The use of in-vehicle timers to take advantage of time-of-use (ToU) rates could help minimise stress on the electrical grid whilst also saving money for consumers.

- Combined smart and cost-oriented charging. Combining smart charging and the least marginal-cost approach lowers real-time prices and, therefore, increases the share of renewable energy such as wind (Dallinger et al., 2012).

- Renewable energy- or low emission-oriented charging. This strategy aims to increase environmental performance or avoid the negative impact of GHG and air pollutant emissions. The measure shifts charging times to periods of high and/or surplus renewable energy generation.

\section{Impacts of Electric Vehicle Penetration on Mobility Patterns: Literature Review}

\subsection{Trip Distance}

Newman and Kenworthy's (1989) pioneering research shows the relationship between population density and energy use: per capita automobile usage, represented by gasoline used per capita, drops with rising area population density.

More recent research in line with Newman and Kenworthy's seminal work considers the use of PEVs:

Schuller and Hoeffer (2014) assess the impact of individual socio-demographic mobility patterns on the potential to utilise renewable energy for PEV charging. They find that shorter driving distances increase the relative adoption potential of renewables to generate electricity for PEVs.

Glazebrook and Newman (2018) foresee the emergence of a polycentric city linked by fast electric rail, with local access based on autonomous 'community'-owned electric cars, including small-scale electric cars and buses, supplemented by bicycles, electric bikes, and scooters, with all electricity generated from renewables. The city would likely have, amongst others, (i) an increased concentration of jobs, residents, and activities along old transit corridors and in satellite cities and sub-centres clustered around intensive rail systems; (ii) increasing housing density in all parts of the city; and (iii) a concomitant decline in the share of 'dispersed' activities.

This view on the emerging trend of urban compacting is shared by many researchers such as Vandecasteele et al. (2019), suggesting that new urban developments are promoting higher- 
density housing, thereby making public transport more efficient whilst also promoting a new work-live-play urban model whereby all necessary services, housing, and entertainment are within walking distance. The research suggests that legislation and governance measures are needed to ensure that new transport modes such as autonomous EVs complement rather than compete with public transport.

Thakur et al. (2016), however, find that the autonomous era will be shaped by two competing dynamics. First, new autonomous ride-sourcing services may catalyse a move away from private vehicle ownership, which will increase the marginal cost of travel and encourage urban consolidation and regeneration. Second, reduced perceived travel costs will likely encourage citizens to accept longer travel times. A combination of denser inner cores and sprawling development on the urban fringes can be expected.

Ahmadian et al. (2019) believe that PEV penetration might lead to longer travel distances and times and not compact urban form. The combination of PEV penetration and the use of solar photovoltaic (PV) residential roof-based electricity to charge PEVs will result in comparatively clean and free well-to-wheel energy. Solar PV electric energy use by buildings and transport favour lower-density, non-compact urban form as there is an inverse correlation between urban density and transport energy: residential roof-mounted solar PVs in lower-density urban areas can potentially generate more energy than is required for typical transport needs in urban areas. Suburbia can power transport in the city and still have energy to spare. This does not necessarily mean that vehicles need to be charged at home, as various options of distributing renewable energy are assumed.

Byrd et al. (2013) find that low-density suburbia is the most efficient collector of solar energy and generates excess electricity to power daily transport needs and contribute to peak daytime electrical loads in the city centre.

\subsection{Trip Origin-Destination and Schedule}

PEVs should be charged using an energy source that will reduce carbon emissions and avoid increasing the load on the local electric power grid. This system requires smart charging schemes that can be implemented in public charging facilities.

Determining the optimal location of such facilities has been an important research subject for almost 10 years. Various studies recommend different optimisation rules. Three studies are worth mentioning here:

- Frade et al. (2010) aimed to maximise demand covered within an acceptable level of service and to define the number and capacity of the stations to be installed in Lisbon, Portugal.

- Wagner et al. (2014) used three optimisation objectives to determine locations of charging points and stations in Amsterdam, The Netherlands: maximising charging point utilisation, minimising PEV drivers' range anxiety, and maximising stations' visibility.

- Vazifeh et al. (2019) used call data records to apply a new methodology in Boston, US, and to optimise PEV charging locations. The objective was to cover the entire demand region whilst minimising drivers' total excess driving distance to reach charging stations, related energy overhead, and number of charging stations. 
Only a few researchers, however, have studied the effects of charging facility placement on mobility:

Wagner et al. (2014), for example, found that people charge their vehicles at stores where they spend a lot of time. In places such as bakeries, for instance, people stay for too short a time to warrant plugging their vehicles into a charge point outlet.

Çolak et al. (2016) studied how to harmonise smart charging with trip schedules. They analysed a coupling of two unique large datasets on urban mobility and EV energy consumption. Amongst others, they found high temporal flexibility of charging sessions, i.e., vehicles are parked for longer periods than required to fully charge them, allowing room for improvement in scheduling PEV charging. The researchers found a method to shave the daily peak power to alleviate the load on the power grid: peak power values can be shed by delaying charging and adjusting the arrival hours without imposing constraints on departure times, and without violating charging continuity or delaying departure time.

\section{Discussion}

Reducing GHG emissions, strengthening energy security by reducing imports of petroleum products used for transport fuels, and improving urban air quality are amongst the mostfrequent arguments invoked in favour of PEV penetration.

Whilst PEVs should reduce tank-to-wheel (downstream) air pollution in urban areas and reduce demand for gasoline and diesel fuels, ASEAN countries face the big challenge of deploying PEVs to reduce GHG emissions. The countries are mostly dependent on carbonintensive energy sources such as coal and natural gas to generate electricity.

In countries dependent on fossil fuel-based power plants, such as Indonesia, Malaysia, Viet Nam, and Thailand, policies to ensure energy-efficient urban mobility are highly important. The use of electricity by PEVs should be minimised by encouraging compact urban forms and structures and restraining urban sprawl. Doing so will minimise travel by private car and promote the use of mass public transport and soft modes such as walking and cycling. Newman and Kenworthy's density theory holds in this situation, whilst increasingly compacting urban forms (Glazebrook and Newman, 2018; Vandecasteele et al., 2019) is the trend of the future. Only when a country develops home-based solar PV electricity in suburbia to feed residential and EV needs can urban-form policies be relaxed.

Mobility-related policy measures should be linked to the charging mechanism. The impacts of PEV charging on the grid and on power generation are so far negligible, but battery costs are declining continuously, electricity is cheaper than gasoline and diesel, and urban mobility and car ownership are rising in ASEAN countries. All these factors might lead to a tipping point for EV market penetration. A strategy is needed to implement different charging schemes to avoid pressure on the electric grid and to maximise the use of low-carbon power generation.

Studies in some PEV front-runner countries show that unregulated charging will add pressure to the urban electric grid when household electricity demand is at its peak. Uncontrolled charging after work threatens network grid security, which is generally vulnerable in ASEAN countries. In countries that generate electricity in fossil fuel-intensive 
power plants, additional electricity for charging PEVs in the late afternoon (a peak load period) comes mostly from coal- and gas-fired plants.

ASEAN countries should manage their PEV charging mechanisms to avoid peak periods and take advantage of periods when renewables are available to meet additional demand. Locations of public charging facilities should encourage electricity consumption during periods of lowest grid load and when renewable-based electricity is available. For instance, public charging facilities can be installed in workplaces or in parking facilities of stores where people spend a long time when grid load is low and renewable-based electricity is available. PEVs can be allocated special parking spaces or access.

\section{Recommendations and the Way Forward}

First, because they use a high percentage of fossil fuel to generate electricity, ASEAN countries must adhere to policies that increase urban density and compactness and stop urban sprawl. Generalised costs of PEV travel will continue to decrease significantly, which will increase PEV adoption and average mileage. Only when a country develops renewables such as home-based solar PV energy can it relax its policies on urban sprawl.

Second, ASEAN countries need to locate PEV charging facilities in a way that avoids stress on the electric power grid and maximises the use of renewables.

This research is a preliminary step in building an urban mobility development framework to maximise the benefits of PEV penetration in ASEAN countries' urban areas. The task is challenging because countries and regions produce electricity in different ways, and urban areas vary greatly in structure, characteristics, and mobility patterns.

We recommend two research axes:

- Conduct a more comprehensive literature study on the relationship between EV penetration, mobility patterns, and urban forms.

- Conduct an empirical study on how charging facilities are located in Asian and ASEAN countries' urban regions and how this might interfere with current mobility patterns and policies.

\section{References}

Aji, G. A. (2017), 'PLN to Install 1,000 Electric Vehicle Charging Posts in Jakarta', Tempo.co (English version), 14 December. https://en.tempo.co/read/914119/pln-to-install1000-electric-vehicle-charging-posts-in-jakarta (accessed 13 June 2019).

Akhyar, T. (2019), 'Electric car production can generate forex savings of IDR 789 Trillion', Netralnews.com (English version), 9 May.

https://en.netralnews.com/news/business/read/26798/electric.car.production.can. generate.forex.savings.of.idr.789.trillion (accessed 27 June 2019).

Bačeković, I. and P.A. Østergaard (2018), 'Local Smart Energy Systems and Cross-System Integration', Energy, 151, pp.812-25. 
Brandmayr, C., D. Benton, A. George, and C. Kumar (2017), People Power: How Consumer Choice Is Changing the UK Energy System. Green Alliance. https://www.greenalliance.org.uk/people power consumer choice.php (accessed 22 March 2019).

Byrd, H., A. Ho, B. Sharp, and N. Kumar-Nair (2013), 'Measuring the Solar Potential of a City and Its Implications for Energy Policy', Energy Policy, 61, pp.944-52.

Chan, C. C. and Y. S. Wong (2004), 'Electric Vehicle Charge Forward', IEEE Power \& Energy Magazine, 2(6), pp.24-33.

Chen, X., H. Zhang, Z. Xu, C. P. Nielsen, M. B. McElroy, and J. Lu (2018), 'Impacts of Fleet Types and Charging Modes for Electric Vehicles on Emission under Different Penetrations of Wind Power', Nature Energy, 4, pp.413-21.

CNN Indonesia (2018, 'Target ESDM Bangun 10 Ribu SPLU pada 2050', 6 October. https://www.cnnindonesia.com/teknologi/20181005090713-384-335919/targetesdm-bangun-10-ribu-splu-pada-2050 (accessed 13 June 2019).

Çolak, S., E. C. Kara, S. J. Moura, and M. C. González (2016), 'Coupling Electric Vehicle Charging with Urban Mobility'. Department of Civil \& Environmental Engineering, MIT, Cambridge, MA, USA. http://humnetlab.mit.edu/wordpress/wpcontent/uploads/2016/03/EV Mobility.pdf (accessed 13 June 2019).

Dallinger, D., Gerda, S., and Wietschel, M. (2013), 'Integration of intermittent renewable power supply using grid-connected vehicles - A 2030 case study for California and Germany'. Applied Energy, 104, 666-682.

Fitzgerald G. and C. Nelder (2017), 'From Gas to Grid: Building Charging Infrastructure to Power Electric Vehicle Demand'. Rocky Mountain Institute. https://rmi.org/insight/from gas to grid/ (accessed 4 July 2019).

Frade, I., A. Ribeiro, G. Gonçalves, and A. P. Antunes (2011), 'Optimal Location of Charging Stations for Electric Vehicles in a Neighbourhood in Lisbon, Portugal', Transportation Research Record Journal of the Transportation Research Board, 2252 (1), pp.91-98.

Glazebrook, G. and P. Newman (2018), 'The City of the Future', Urban Planning, 3(2), pp.120, DOI: 10.17645/up.v3i2.1247.

https://www.researchgate.net/publication/324732295 The City of the Future (accessed 5 July 2019).

Government of Indonesia (2019), Presidential Decree 22/2017 on the General Planning of National Energy (RUEN) (in Bahasa Indonesia). https://www.hukumonline.com/pusatdata/detail/lt58ed9d355f616/node/534/perat uran-presiden-nomor-22-tahun-2017 (accessed 13 June 2019).

Hall, D. and N. Lutsey (2017), Emerging Best Practices for Electric Vehicle Charging Infrastructure, White Paper. Washington, DC: The International Council on Clean Transportation. https://www.theicct.org/sites/default/files/publications/EVcharging-best-practices ICCT-white-paper 04102017 vF.pdf (accessed 11 December 2018). 
InsideEVs (2013), 'Japan Extends EV Subsidy Program'. https://insideevs.com/news/319125/japan-extends-ev-subsidy-program/ (accessed 1 July 2019).

InsideEVs (2018a), 'Japan's EV Infrastructure Is Massive, Electric Car Sales Not So Much'. https://insideevs.com/news/338290/japans-ev-infrastructure-is-massive-electriccar-sales-not-so-much/ (accessed 1 July 2019).

InsideEVs (2018b), 'Delhi Would Like To Achieve 25\% Electric Car Penetration By 2023'. https://insideevs.com/news/341749/delhi-would-like-to-achieve-25-electric-carpenetration-by-2023/ (accessed 3 July 2019).

International Energy Agency (IEA) (2019), Global PEV Outlook 2019: Scaling-up the transition to electric mobility. Paris: IEA.

Kasten, P., J. Bracker, M. Haller, and J. Purwanto (2016), 'Assessing the status of electrification of the road transport passenger vehicles and potential future implications for the environment and European energy systems'. Final Report - Task 2, Specific Contract under Framework Contract EEA/ACC/13/003, Trinomics BV, Rotterdam, 74p. https://www.oeko.de/fileadmin/oekodoc/Assessing-the-status-ofelectrification-of-the-road-transport-passenger-vehicles.pdf (accessed 22 March 2019).

Lutsey, N., M. Grant, S. Wappelhorst, and H. Zhou (2018), Power Play: How Governments Are Spurring the Electric Vehicle Industry. Washington, DC: The International Council on Clean Transportation.

Martin, C., F. Starace, and J-P. Tricoire (2018), Electric Vehicles for Smarter Cities: The Future of Energy and Mobility. Geneva: World Economic Forum.

Marklines (2019). www. marklines.com/portal top en.html (accessed 13 June 2019).

Nicholls, A., A. M. Baisden, B. Lakshminarasimhan, and X. Boucherat (2018), Special report: The ASEAN auto industry. United Kingdom: Automotive World Ltd.

Nunes, P., T. Farias, and M. C. Brito (2015), 'Day Charging Electric Vehicles with Excess Solar Electricity for A Sustainable Energy System', Energy, 80, pp.263-74.

Raposo Alonso, and M. B. Ciuffo (eds.) (2019), The future of road transport - Implications of automated, connected, low-carbon and shared mobility. Luxembourg: European Commission.

Schill, W-P. and C. Gerbaulet (2015), 'Power system impacts of electric vehicles in Germany: Charging with coal or renewables?' Applied Energy, 156, 15 October, pp.185-96.

Schuller, A. and J. Hoeffer (2014), 'Assessing the Impact of PEV Mobility Patterns on Renewable Energy Oriented Charging Strategies', 8th International Renewable Energy Storage Conference and Exhibition, IRES 2013, Energy Procedia, 46, pp.3229.

https://reader.elsevier.com/reader/sd/pii/S1876610214001714?token=9FB4C4BBB 8E9AA9E64F54B81DF1C5B2DBC84995279FA3906EEF5021F272C5E698E748C554946 DAE322BB5AE283CF6078 (accessed 13 June 2019). 
Soeriaatmadja, W. (2019), 'Indonesia charging ahead with electric vehicle ambitions', The Straits Times, 15 January. https://www.straitstimes.com/asia/se-asia/indonesiacharging-ahead-with-electric-vehicle-ambitions (accessed 13 June 2019).

Suehiro, S. and A. J. Purwanto (forthcoming), Study on Electric Vehicle Penetration's Influence on 3Es in ASEAN, ERIA Research Project Report. Jakarta: Economic Research Institute for ASEAN and East Asia.

Thakur, P., R. Kinghorn, and R. Grace (2016), 'Urban form and function in the autonomous era', Australasian Transport Research Forum 2016 Proceedings, 16-18 November, Melbourne Australia. https://www.atrf.info/papers/2016/files/ATRF2016 paper 138.pdf (accessed 14 June 2019).

Transportation Research Board and National Research Council (2015), Overcoming Barriers to Deployment of Plug-in Electric Vehicles. Washington, DC: The National Academies Press. https://doi.org/10.17226/21725 (accessed 4 July 2019).

United Nations (2018), 'World Urbanization Prospects: The 2018 Revision'. https://population.un.org/wup/ (accessed 25 June 2019).

Vakakos, M. (2013), 'The Impact of electric drive vehicles on travel patterns and the urban form of Lisboa Metropolitan Area'. Dissertation for a master's degree in complex transport infrastructure systems, MIT Portugal Program, Técnico Lisboa, Lisbon, Portugal.

Vandecasteele I., C. Baranzelli, A. Siragusa, and J.P. Aurambout (eds.) (2019), The Future of Cities - Opportunities, challenges and the way forward. Luxembourg: European Commission. https://ec.europa.eu/jrc/en/publication/eur-scientific-and-technicalresearch-reports/future-cities (accessed 5 July 2019).

Vazifeh, M., H. Zhang, P. Santi, and C. Ratti (2019), 'Optimizing the deployment of electric vehicle charging stations using pervasive mobility data', Transportation Research Part A, 121, pp.75-91.

Wagner, S., T. Brandt, and D. Neumann (2014), 'Smart City Planning - Developing An Urban Charging Infrastructure for Electric Vehicles', Twenty Second European Conference on Information Systems, Tel Aviv, Israel.

https://www.researchgate.net/publication/286597848 Smart city planning _Developing an urban charging infrastructure for electric vehicles (accessed 14 June 2019). 